\title{
Endovascular Aneurysm Sealing (EVAS) in Combination with the Chimney Technique for the Treatment of Aortic Allograft Rupture
}

Rustum $\mathbf{S}^{1 *}$, Meyer $\mathbf{B}^{2}$, Hinrichs $\mathrm{J}^{2}$, Aper $\mathrm{T}^{1}$, Haverich $\mathrm{A}^{1}$ and Wilhelmi $\mathbf{M}^{1,3}$

${ }^{1}$ Division of Vascular and Endovascular Surgery, Department of Cardiothoracic, Transplantation, and Vascular Surgery, Hannover Medical School, Hannover, Germany ${ }^{2}$ Institute for Radiology, Hannover Medical School, Hannover, Germany

${ }^{3}$ Center for Competence for Cardiovascular Implants, Hannover Medical School, Hannover, Germany

\begin{abstract}
We report on a 62-year old male patient with complicated surgical history and actual covered ruptures of an aortic allograft. Considering the hostile abdomen we decided for an interventional/endovascular treatment. We implanted an aortic-(EVAS; Nellix ${ }^{\circledR}$ ) as well as two renal stentgrafts in „chimney "technique. Following an uneventful perioperative course the patient was discharged on $14^{\text {th }}$ postoperative day. This unusual case demonstrates that endovascular aneurysm sealing especially in combination with the chimney technique may be a feasible and reasonable alternative approach for the urgent/emergent treatment of aortic (prosthesis) associated complications where traditional surgical approaches are not applicable.
\end{abstract}

\section{Keywords: EVAS, Homograft, Graft infection}

\section{Case Report}

We report on the case of a pleasant 62-year old male patient, who was admitted to an external hospital 2 years ago due to acute lower back pain. Further work up revealed a $9 \mathrm{~cm}$ juxtarenal aortic aneurysm so that the patient was scheduled for open aneurysm repair. However, the intraoperative course was complicated due to accidental damage of the duodenum and the jejunum so that the abdomen was closed without aortic repair. Additionally he underwent re-laparotomy for cholecystectomy and partial resection of the duodenum and the jejunum a few weeks later. Subsequently it was attempted to treat the aortic aneurysm by endovascular implantation of an aorto-biiliac stentgraft (COOK inc., Bloomington, IN, USA). However, unfortunately the stentgraft could not be placed within the left iliac artery so that intraoperatively it was decided to occlude the left common iliac artery with a vascular plug and to perform a femorofemoral crossover bypass instead.

Four months following this complicated course the patient was admitted to our hospital due a suspected infection of the aortic endograft as well as an endoleak type Ia. Beside, meanwhile the aortic aneurysm had grown to a maximal diameter of $13 \mathrm{~cm}$. Due to multiple previous laparotomies we chose a retroperitoneal surgical approach removed all stentgrafts, the femoro-femoral crossover bypass as well as the left iliac vascular plug and placed an aorto-bi-iliac allograft. Following an uneventful perioperative course the patient could be discharged in good physical condition on the $34^{\text {th }}$ post-op day with appropriate antibiotics and antifungal for the next 6 weeks.

Another nine months later, the patient presented in the external hospital again because of a $3 \mathrm{~cm}$ measuring aneurysm of the right common iliac artery (could not be reached/treated via the retroperitoneal approach). Another stentgraft was placed and following an initially uneventful course the patient was discharged from hospital again. However, starting shortly thereafter the patient complained about left-sided lower back pain with increasing intensity so that he was re-admitted to the external hospital again. A computed tomography angiography revealed a rupture at the left posterior side of the aortic homograft in direct extension of the left iliac stent graft and thus, leading to the assumption, that the homograft might have been puncture damaged by a guide wire at the time of stenting the right iliac artery (Figure 1). Furthermore, an insufficiency at the proximal allograft anastomosis site was suspected so that the patient was admitted to our hospital again for further treatment. Directly after arrival at our institution laboratory work up reveled an elevated C-reactive protein $(252.5 \mathrm{mg} / \mathrm{L})$ and a slowly decreasing hemoglobin level $(8.4 \mathrm{~g} / \mathrm{dL})$, but leukocytes within normal range $(6.8 \mathrm{Tsd} / \mu \mathrm{L})$.

Given the complicated surgical history with multiple previous trans- and retroperitoneal abdominal surgical interventions leading to a hostile abdomen and despite a potential graft infection due to

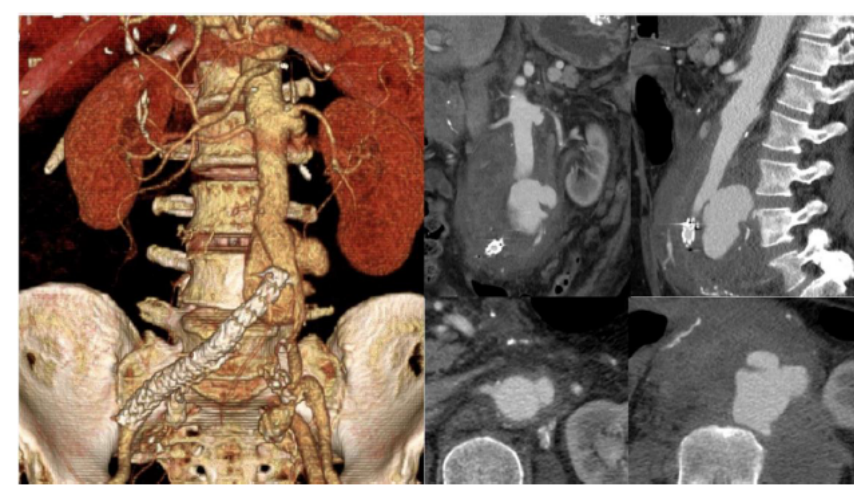

Figure 1: A computed tomography angiography revealed a rupture at the left posterior side of the aortic homograft.

*Corresponding author: Saad Rustum, MD, Division of Vascular- and endovascular Surgery, Department of Cardiothoracic, Transplantation, and Vascular Surgery, Hannover Medical School, Hannover, Germany, Carl NeubergStrasse 1, 30625 Hannover, Germany, Tel: +49-511-532-6589; Fax: +49- 511-5325404; E-mail: Rustum.saad@mh-hannover.de

Received August 16, 2017; Accepted August 25, 2017; Published August 29, 2017

Citation: Rustum S, Meyer B, Hinrichs J, Aper T, Haverich A, et al. (2017) Endovascular Aneurysm Sealing (EVAS) in Combination with the Chimney Technique for the Treatment of Aortic Allograft Rupture. J Vasc Med Surg 5: 334. doi: 10.4172/2329-6925.1000334

Copyright: $\odot 2017$ Rustum S, et al. This is an open-access article distributed under the terms of the Creative Commons Attribution License, which permits unrestricted use, distribution, and reproduction in any medium, provided the original author and source are credited. 
Citation: Rustum S, Meyer B, Hinrichs J, Aper T, Haverich A, et al. (2017) Endovascular Aneurysm Sealing (EVAS) in Combination with the Chimney Technique for the Treatment of Aortic Allograft Rupture. J Vasc Med Surg 5: 334. doi: 10.4172/2329-6925.1000334

elevated C-reactive protein levels it was decided to perform another endovascular procedure. Taking into account the narrow lumen of the aortic allograft (allograft diameter: $2.1 \mathrm{~cm}$ ) with limited space to place a "conventional" aorto-bi-iliac stentgraft as well as the suspected insufficiency at the proximal anastomosis side without a suitable infrarenal landing zone, we decided to perform an endovascular aneurysm sealing in combination with the Chimney technique. Therefore, VIABAHN ${ }^{\circledR}$ stentgrafts $\left(7 \mathrm{~mm} \times 100 \mathrm{~mm}\right.$; W.L. Gore $\left.{ }^{\mathrm{TM}}\right)$ were initially placed in cranial direction via a left brachial approach in the renal arteries and then two Nellix ${ }^{\circledR}$ stentgrafts $(10 \mathrm{~mm} \times 120$ $\mathrm{mm}$; Endologix ${ }^{\mathbb{R}}$ ) were placed via the left and the right femoral arteries within the aortic allograft. The endobags were filled with a total of only $25 \mathrm{~mL}$ Polymer till the inflation pressure was $180 \mathrm{mmHg}$. Subsequently both Nellix ${ }^{\circledR}$ stentgrafts were extended by placing additional stentgrafts $\left(12 \mathrm{~mm} \times 80 \mathrm{~mm}\right.$; Fluency Plus Vascular Stent Graft ${ }^{\circledR}$; BARD peripheral vascular, Inc., USA) to secure distal fixation within both iliac arteries (Figure 2).

The perioperative course was uneventful so that the patient could be discharged from hospital on POD 14. A computed tomography angiography prior to discharge revealed no evidence for an aortic rupture or endoleakage and laboratory tests revealed a declining C-reactive protein $(42.3 \mathrm{mg} / \mathrm{L})$ and leukocytes within normal range (3.7 Tsd/ $\mu \mathrm{L}$ ). Now, three months later, he is still doing well and the regular laboratory tests give no hints for infection or bleeding (Figure 3).

\section{Discussion}

Aortic graft infection is a known life-threatening condition with a mortality rate between $8 \%$ and $27 \%[1,2]$. However, it occurs infrequently, with a reported incidence of $1 \%$ to $6 \%$ [3-5] and is treated

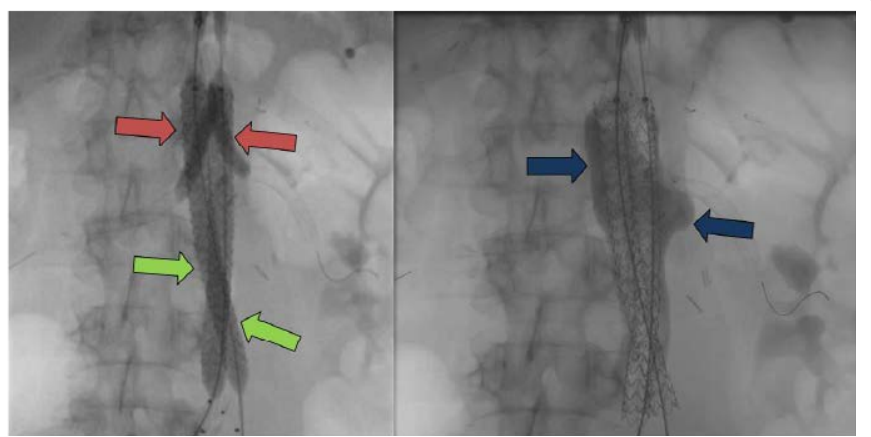

Figure 2: Distal fixation within both iliac arteries

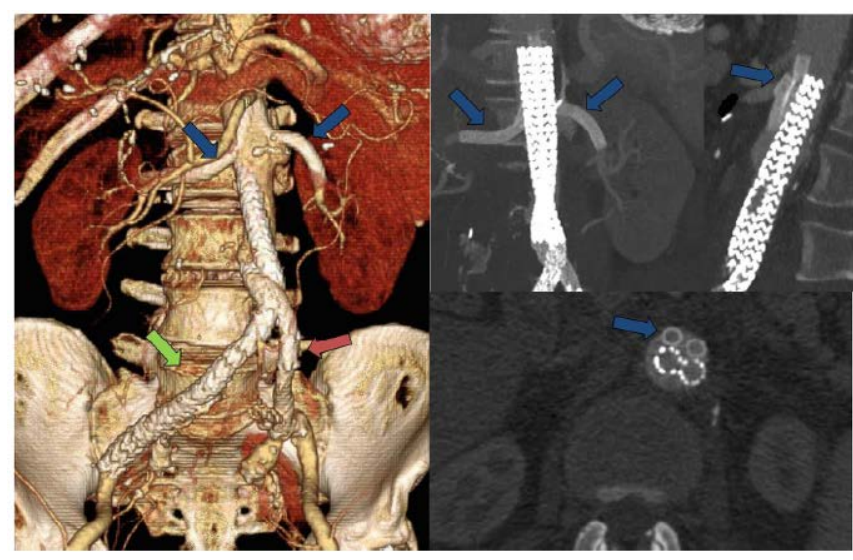

Figure 3: No infection or bleeding. in the majority of cases by total or partial graft excision followed by anatomic or extra-anatomic bypass surgery using diverse kinds of bypass materials [6]. Graft sparing approaches are only performed in high risk patients and/ or those who are not suitable for surgery due to other reasons, e.g., severe comorbid illnesses, a hostile abdomen, complicated bypass grafts etc. However, although associated with high mortality rates few reports are accessible demonstrating that non-excisional treatment options, i.e., endovascular interventions or even medical therapy through drainage followed by irrigation with antibiotics and antiseptic agents and the systemic administration of antibiotics can be successful in some cases of graft infections as well [711]. In this sense some authors prefer conservative treatments options arguing that even suboptimal therapy in high-risk patients allowing some more years of life might be better than being extremely radical [12].

In our present case we chose a graft preserving endovascular procedure in combination with long-term antibiotic therapy who otherwise would have most probably not survived if a major surgical approach would have been performed. However, a technical challenge was to insert an aorto-bi-iliac stentgraft in a $2 \mathrm{~cm}$ wide allograft lumen without adequate proximal and distal landing zone. Furthermore, the "traditional" Chimney procedure, otherwise allowing to generate a suitable proximal landing zone seemed to be not applicable in this case because of potential gutter formation and the associated risk of endoleakage type-Ia [13].

In spite of these difficulties and although there is few experience by treatment the ruptured abdominal aortic aneurysma with the Nellix endosystem and in especially in conjunction with the chimney procedure $[14,15]$, we decided to use the Nellix ${ }^{\circledR}$ endosystem for both reasons: (i) to allow for secure sealing of the aortic rupture side as well as the insufficiency of the proximal anastomosies side and (ii) to safely seal potential gutters around the renal stentgrafts.

\section{Conclusion}

Although surgery with complete excision remains the first line treatment in graft infections, there is no "one fits all" treatment strategy for all those cases. Our current case demonstrates that the Nellix Endovascular Aneurysm Sealing System ${ }^{\circledR}$ (EVAS) can be inserted comfortably even in a case with complex vascular morphology and narrow aortic lumen and additionally, might be extremely helpful in safely avoiding gutter associated endoleakage type Ia when using the Chimney technique.

\section{References}

1. Bisdas T, Bredt M, Pichlmaier M, Aper T, Wilhelmi M, et al. (2010) Eight-year experience with cryopreserved arterial homografts for the in situ reconstruction of abdominal aortic infections. J Vasc Surg 52: 323-330.

2. Hart JP, Eginton MT, Brown KR, Seabrook GR, Lewis BD, et al. (2005) Operative strategies in aortic graft infections: is complete graft excision always necessary? Ann Vasc Surg 19: 154-160.

3. Calligaro KD, Veith FJ (1991) Diagnosis and management of infected prosthetic aortic grafts. Surgery 110: 805-813.

4. Goldstone J, Moore WS (1974) Infection in vascular prostheses: clinical manifestations and surgical management. Am J Surg 128: 225-233.

5. Jamieson GG, De Weese JA, Rob CG (1975) Infected arterial grafts. Ann Surg 181: 850-852.

6. O'Connor S, Andrew P, Batt M, Becquemin JP (2006) A systematic review and meta-analysis of treatments for aortic graft infection. J Vasc Surg 44: 38-45.

7. Tambyraja AL, Chalmers RT (2003) Conservative management of MRSA periaortic graft abscess. Ann Vasc Surg 17: 676-677.

8. Nakazawa T, Yasuhara H, Shigematsu H, Muto T (1999) Conservative 
Citation: Rustum S, Meyer B, Hinrichs J, Aper T, Haverich A, et al. (2017) Endovascular Aneurysm Sealing (EVAS) in Combination with the Chimney Technique for the Treatment of Aortic Allograft Rupture. J Vasc Med Surg 5: 334. doi: 10.4172/2329-6925.1000334

Page 3 of 3

management of a methicilin-resistant Staphylococcus aureus (MRSA)-infected aortobifemoral graft: report of a case. Surg Today 29: 280-283.

9. Calligaro KD, Veith FJ, Yuan JG, Gargiulo NJ, Dougherty MJ (2003) Intraabdominal aortic graft infection: complete or partial graft preservation in patients at very high risk. J Vasc Surg 38: 1199-1205.

10. Kawashima M, Torisu T, Kamo Y, Iwabuchi A (1980) The treatment of pyogenic bone and joint infections by closed irrigation-suction. Clin Ortho 148: 240-244.

11. Soravia-Dunand VA, Loo VG, Sali IE (1999) Aortitis due to salmonella: report of 10 cases and comprehensive review of the literature. Clin Infect Dis 29: 862-868.

12. Kan CD, Lee HL, Yang YJ (2007) Outcome after endovascular stent graft treatment for mycotic aortic aneurysm:a systematic review. J Vasc Surg 46: 906-912.

13. Donas KP, Eisenack M, Panuccio G, Austermann M, Osada N, et al. (2012) The role of open and endovascular treatment with fenestrated and chimney endografts for patients with juxtarenal aortic aneurysms. J Vasc Surg 56: 285-290.

14. Reijnen MM, de Bruin JL, Mathijssen EG, Zimmermann E, Holden A, et al (2016) Global Experience With the Nellix Endosystem for Ruptured and Symptomatic Abdominal Aortic Aneurysms. J Endovasc Ther 23: 21-28.

15. Malaj A, Martinelli O, Fresilli M, Picone V, Giglio A et al. (2015) Treatment of a Juxtarenal Aneurysm with a Parallel Graft in the Left Renal Artery and Polymer-Based Technology to Seal the Entire Aneurysmal Sac. Ann Vasc Surg 29: 1662.e19-22. 